\title{
Subglottic secretion drainage for ventilator-associated pneumonia prevention: an underused efficient measure
}

\author{
Jean-Claude Lacherade, Marie-Ange Azais, Caroline Pouplet, Gwenhael Colin \\ District Hospital Center, Medical-Surgical Intensive Care Unit, La Roche-sur-Yon, France \\ Contributions: (I) Conception and design: All authors; (II) Administrative support: All authors; (III) Provision of study materials or patients: All \\ authors; (IV) Collection and assembly of data: All authors; (V) Data analysis and interpretation: All authors; (VI) Manuscript writing: All authors; (VII) \\ Final approval of manuscript: All authors. \\ Correspondence to: Jean-Claude Lacherade, MD. District Hospital Center, Medical-Surgical Intensive Care Unit, La Roche-sur-Yon, France. \\ Email: jean-claude.lacherade@chd-vendee.fr.
}

\begin{abstract}
Subglottic secretion drainage (SSD) is one of the recommended strategies to prevent ventilatorassociated pneumonia (VAP) with a high level of evidence, especially regarding early-onset pneumonia. All meta-analysis found that the use of SSD reduces VAP occurrence with a relative risk (RR) reduction of $45 \%$. In some of them, SSD reduces the duration of mechanical ventilation (MV) but without beneficial effect on intensive care unit (ICU) or hospital mortality. In spite of the edited recommendations, SSD has not been widely implemented in ICUs and remains underused. Several factors could account for this: doubts on the innocuousness of using SSD, persisting reservations on the SSD effect on other outcomes than VAP, a high variability in the volume of secretions suctioned between patients and, for each individual patient, during the period of MV and the initial increased expense of the specific endotracheal tubes (ETs) allowing SSD which limits the availability of these devices.
\end{abstract}

Keywords: Prevention; ventilator-associated pneumonia (VAP); subglottic secretions; drainage; intensive care unit (ICU)

Submitted Oct 08, 2018. Accepted for publication Oct 11, 2018.

doi: $10.21037 /$ atm.2018.10.40

View this article at: http://dx.doi.org/10.21037/atm.2018.10.40

\section{Introduction}

The occurrence of ventilator-associated pneumonia (VAP) has an undeniable impact. It increases the duration of mechanical ventilation (MV) and the length of stay in intensive care unit (ICU) by a factor of 2 to 3, as well as incurring an increase in antibiotics administered and hospital expenditures (1-4). The attributable mortality of VAP remains controversial: recent published studies (analysis from a large-scale database or meta-analysis based on VAP prevention studies) estimated it to range between $4.4 \%$ and $9 \%(5,6)$. Thus, a prevention policy aiming to reduce VAPs remains an important element of the overall management for patients admitted to ICUs and requiring MV (7).

VAP results from microbial invasion of the normally sterile lower respiratory tract and lung parenchyma, which can then overwhelm the host's defence to establish infection. The primary route of bacterial entry into the lower respiratory tract is via aspiration of bacteria-contaminated secretions which accumulate above the endotracheal tube (ET) cuff (8-10). The repeated micro-aspirations of these secretions, so-called subglottic secretions, are due to the formation of longitudinal folds within the cuff wall (11) and occur up to $77 \%$ of patients intubated for longer than three days $(12,13)$. Thus, subglottic secretion drainage (SSD) has been proposed to be included in the bundles of VAP prevention. Nevertheless, the SSD requires specific ETs including a separate dorsal lumen that opens immediately above the ET tube cuff.

Initially the impact of SSD on the incidence of VAP will be discussed, as well as its use in ICUs. We will, 
after, discuss the various questions on hold with the use of the SSD which represent so many breaks to its diffusion.

\section{SSD and VAP}

Since 1992 when the first study on this topic was published (14), the impact of SSD on VAP incidence has continued to be assessed extensively: approximately 20 randomized monocentric trials (14-35), 3 multicentre studies (36-38) and 7 meta-analyses (39-45). It is important to emphasize that studies used different criteria for patient enrolment (inclusion according to a predicted duration of ventilation over 24 or 72 hours), that 3 studies specifically targeted postoperative cardiac surgery $(17,21,24)$ and that 4 studies assessed the overall influence of SSD and the cuff material (polyurethane) (27) or SSD and the cuff form (28); and SSD and continuous cuff pressure control $(15,21)$.

According to the last meta-analysis published in 2016 (43), subglottic secretions drainage led a statistically significant reduction in the overall incidence of VAPs by a factor $\sim 2$ [relative risk (RR) of VAP occurrence 0.55, $95 \%$ confidence interval (CI): $0.48-0.63, \mathrm{P}<0.00001]$. A similar result is observed considering only trials with high methodological level (43).

The effect of SSD appears primarily on the incidence of early-onset VAP ( $R R=0.23,95 \%$ CI: $0.13-0.43, \mathrm{P}<0.00001$ ) and not on late-onset cases VAP ( $\mathrm{RR}=0.80,95 \% \mathrm{CI}$ : $0.62-1.02)$. This statement should be taken into account with cautious, since none of the published studies were experimentally designed to demonstrate, in intention to treat, any effect on late-onset VAP.

In addition, the average number of subjects with SSD strategy to prevent an episode of VAP is estimated to be equal to $11(37,44)$. Furthermore, the use of SSD led to an increased delay of 4 days prior to the first VAP occurrence following the initiation of MV (43). This result suggests the potential complementarity of SSD with additional strategies aimed at reducing $\mathrm{MV}$ exposure such as sedation and/or weaning protocols.

Thus, SSD is widely advocated to prevent VAP. National guidelines in the United States, Canada, and parts of Europe recommend using ETs with SSD (46-48). However, it should be noted that these recommendations are only for preventing early-onset cases of VAP (occurring up to the 5 th day of ventilation). Currently, despite numerous publications, the efficiency of the drainage of subglottic secretion remains controversial (39,49-51).

\section{Diffusion of SSD in ICUs}

Ten years following the original publication, implementation of SSD remained confidential: only $4 \%$ of Canadian and French ICUs reported using SSD in 2000 (52). In parallel published data (clinical trials, meta-analysis and guidelines), the use of SSD has increasingly spread over the last ten years, from about $20 \%$ of the ICUs in North America in 2008 (53) to reach $50 \%$ of the ICUs in United Kingdom in 2015 (54). In the aforementioned study, it's interesting to observe apparent better compliance for other components of the UK recommended ventilator care bundle (semi-recumbent position in 100\% of cases, sedation level assessment in $93 \%$ and cuff pressure measurement in $86 \%$ for example).

Clearly, there is a gap between the evidence of the SSD efficacy for preventing VAP and its underuse in routine care in ICUs (55). This reflects that persistent doubts or unresolved questions for performing SSD remain.

\section{Uncertainties regarding SSD}

\section{Safety of SSD}

The safety of subglottic secretions drainage remains controversial (56). A dual question persists: does SSD directly lead to tracheal lesions? And if so, can these lesions be a source of complications and/or a risk for increasing mortality?

Under certain experimental conditions (on sheep ventilated in ventral decubitus for 72 hours), continuous SSD has been associated with lesions of the tracheal wall (up to the tracheal necrosis) adjacent to the opening of the dorsal lumen (57). Another recent trial studied six patients who were intubated with an $8 \mathrm{~mm}$ Mallinckrodt Hi-Lo Evac ET with intermittent suctioning applied at $-125 \mathrm{mmHg}$ for 15 s. The resulting CT scans demonstrated an entrapment of the tracheal mucosa into the subglottic port of the tube (58). In a very recent study with 53 patients, the global incidence of mucosa tracheal damage was $23 \%$ when SSD was applied (9 patients with erythema, 1 case of oedema and 2 patients with ulcerations) (59). The occurrence of tracheal mucosa injuries was independent of the modality of suction (continuous $v s$. intermittent), even if oedema and ulcerations were only observed when SSD was performed continuously. Nevertheless, neither tracheal necrosis nor post extubation stridor was reported in this study.

In a recent meta-analysis, no difference was observed in post-extubation stridor (RR, 1.58; 95\% CI: 0.68-3.67; 
$\mathrm{P}=0.29$ ) or reintubation ( $\mathrm{RR}, 0.99$; $95 \% \mathrm{CI}: 0.65-1.51$; $\mathrm{P}=0.96$ ) rates between $\mathrm{SSD}$ and control groups (39). In any of the meta-analysis evaluated, performing SSD has never been associated with an increase of the MV duration, or of the ICU length of ICU stay, or with any increase of ICU or hospital mortality.

Finally, the controversy on the safety of SSD remains ongoing, since a dedicated prospective study to this issue, including a long-term systematic follow-up, has not yet been completed.

\section{Variability in the volume of subglottic secretion collected}

This is probably one of the most perturbing aspects for paramedical and medical teams when SSD is installed in ICUs. Undoubtedly the daily volume of subglottic secretion varies for a given patient as well as between two patients $(32,37)$. This variability could be due to several factors. One factor is the subglottic space limitations by the vocal cords at the top, and by the upper part of the cuff at the bottom. This is directly dependent on the patient's morphological characteristics and on the positioning of the ET extremity, more or less close to the carina. Another factor is that the presence of secretions above the endotracheal cuff does not remain constant. Thus, in an observational radiological study, the presence of accumulated secretions above the cuff was only detected on $57 \%$ of patients undergoing respiratory assistance at a given time. In these patients, the volume varied immensely between 2.1 and $18.4 \mathrm{~mL}$ (60). In addition, factors that may alter the cuff's "sealing" properties may also affect secretions volume above the cuff: level of positive expiratory pressure (PEP) $(61,62)$, inspiratory effort (61) but also cuff pressure variations throughout the duration of MV (63). There could also be a dysfunction in the drainage system. Thus, in an observational study of SSD performed continuously on 40 patients, the authors reported dysfunctions in 19 cases, 17 of which were related to the closing of the orifice of the canal collector by the tracheal mucosa (64). Thus, it appeared that performing SSD in a discontinuous manner was associated with collecting a higher mean daily volume of subglottic secretions than with a continuous suctioning $(74 v s .20 \mathrm{~mL}$, respectively, $\mathrm{P}<0.001)(59)$.

Moreover, this issue remains to be clarified: does the volume of subglottic secretions collected influence the occurrence of VAP? Especially, since except from a total absence of subglottic secretions, there is no cut-off value established for specifying that below this threshold, SSD is ineffective in preventing VAP.

\section{Subglottic secretions drainage and duration of MV, length of stay and mortality}

VAP has been repeatedly associated with prolonged MV, length of stay, and increased mortality $(3,65)$. Thus, we could expect that a preventive strategy, such as SSD which led to a substantial decrease in VAP, would be also accompanied by an improvement in these outcomes qualified as being more objective. Publications on SSD do not support such improvement for all these outcomes. This differential effect remains the main criticism for SSD (39). Nevertheless, before considering that hospitals may wish to implement other VAP preventive interventions in priority before SSD, as it was suggested, we should investigate whether these expectations are genuinely achievable?

Except for Zheng and colleagues (35), none of the individual SSD trials have demonstrated reduced MV duration by performing SSD. This observation raised the underlying issue of the expected magnitude of this reduction (in number of days of MV). In considering a trial assessing a preventive VAP strategy, the potential MV duration reduction is the product of the difference in $\mathrm{MV}$ duration observed between patients who developed VAP and those without VAP by the absolute reduction rate (AAR) in VAP observed between the control and the VAP preventive arms of the study. For example, in assuming a MV duration difference between patients VAP+ and patients VAP- of 10 days and an absolute reduction in VAP incidence of 0.1 (10\%) (43), the expected reduction in MV duration will be equal to 1 day. Thus, it would be required over 2,000 patients in each arm of a conventional randomized trial to demonstrate such a difference (assuming a standard deviation of MV duration of 12 days). Clearly the previous randomised clinical trials assessing the effect of SSD did not have the power required to demonstrate any impact on the MV duration. However, the meta-analyses, in which sample size was amplified (more than 3,000 patients), highlighted the paradigm of the significant reduction of the $\mathrm{MV}$ duration ( -1.17 days, with a confidential interval of -2.28 to -0.06$)$ linked with the decrease of VAP incidence (43). Nevertheless, in this meta-analysis, the GRADE evidence quality of this result was only considered as moderate due to heterogeneity between the studies $\left(\mathrm{I}^{2}>50 \%\right)$. Thus, the capacity of SSD to reduce MV duration still remains controversial (39).

All meta-analysis, and let alone all RCTs, assessing the 
SSD impact failed to show that SSD could significantly reduce ICU and hospital mortality (39-45). VAP was associated with a $5 \%$ to $9 \%$ higher risk increase of mortality $(5,6)$ than for non-VAP patients; thus, an ARR $(0.1)$ of VAP (43), may reduce the ICU mortality by $0.5-0.9 \%$. In this situation, a sample size of several tens of thousands of patients would be needed to reach a significant result for ICU mortality. Thus, it appears that future studies on VAP prevention will not have the power to detect any benefit on mortality directly related to the reduced incidence of VAP. Therefore, it is suggested also that ICU (or hospital) mortality is not a reasonable or credible criterion for assessing if a preventive VAP strategy is effective (whatever its nature).

\section{Medico-economic impact of implementing SSD}

Implementing SSD has been assessed by several medicoeconomical evaluations based on theoretical models $(66,67)$ or on models extrapolating data from observed reduction of VAP incidence in using SSD (68-70). Despite the initial extra cost of ETs allowing the SSD, all these evaluations conclude that implementing SSD is a cost-effectiveness preventive strategy.

Nevertheless, these previous medico-economic evaluations have not focused on the issue of the diffusion of the specific ETs for performing SSD. In theory, optimizing SSD implementation in ICUs requires that all the patients which would benefit in using SSD (i.e., patients remaining alive and intubated more than 48 or 72 hours after their ICU admission) will be actually intubated with the specific ET. This means making these ETs available, not only in ICUs, but in all the departments involved in intubating critically ill patients prior to their admission in ICU (emergency wards, operating rooms, prehospital emergency medical services). Moreover, it is difficult to determine, at the time of intubation, which patients will be remained under MV more than 48 hours after their admission in ICU. This implies that all patients requiring mechanical intubation should be intubated with the specific ET. Indeed, by making specific ETs increasingly available, the initial cost overage would significantly increase. However, to limit this initial cost overage, some circumstances, more likely associated with a MV duration above 48 or 72 hours, could represent opportunities to intubate with ETs allowing SSD: non-operative intubation, emergent intubation, admission to neuroscience critical care unit and acute kidney injury (71).
Ultimately, since more conclusive prospective data is lacking, the initial cost of specific ETs for performing SSD remains one of the main obstacles to making SSD more widely available in ICUs. A large multicentre study has been recently completed and could provide other perspectives on this topic (DEMETER study, clinicaltrials.gov identifier: NCT02515617).

\section{Conclusions}

Undeniably, SSD correlates with a significantly decreased VAP incidence. Nevertheless, SSD is not widely used into VAP preventive bundles. The persistent controversies regarding safety, efficacy to reduce the MV duration and the initial overage cost for the specific ETs are the critical points which explain this paradoxical situation. Thus, in ICU, the decision to introduce SSD should take into account the initial VAP incidence as well as the compliance assessment with other preventive VAP measures and the expected outcome. To be efficacious, this preventive management approach must be accompanied by a decision make specific ETs for SSD available in all medical wards involved in the intubation prior to admission in ICU (emergency department, prehospital emergency medical services, operating rooms for patients with organ failure before emergency surgery, for example). Inexorably, SSD's role will need to be re-evaluated in function of the potential industrial advances and the quality of their evaluation (ET cuff material, finer regulation of the cuff pressure, ETs provided with several orifices allowing SSD...).

\section{Acknowledgements}

None.

\section{Footnote}

Conflicts of Interest: The authors have no conflicts of interest to declare.

\section{References}

1. Coffin SE, Klompas M, Classen D, et al. Strategies to prevent ventilator-associated pneumonia in acute care hospitals. Infect Control Hosp Epidemiol 2008;29 Suppl 1:S31-40.

2. Rello J, Ollendorf DA, Oster G, et al. Epidemiology and outcomes of ventilator-associated pneumonia in a large US 
database. Chest 2002;122:2115-21.

3. Safdar N, Dezfulian C, Collard HR, et al. Clinical and economic consequences of ventilator-associated pneumonia: a systematic review. Crit Care Med 2005;33:2184-93.

4. Warren DK, Shukla SJ, Olsen MA, et al. Outcome and attributable cost of ventilator-associated pneumonia among intensive care unit patients in a suburban medical center. Crit Care Med 2003;31:1312-7.

5. Bekaert M, Timsit JF, Vansteelandt S, et al. Attributable mortality of ventilator-associated pneumonia: a reappraisal using causal analysis. Am J Respir Crit Care Med 2011;184:1133-9.

6. Melsen WG, Rovers MM, Koeman M, et al. Estimating the attributable mortality of ventilator-associated pneumonia from randomized prevention studies. Crit Care Med 2011;39:2736-42.

7. Kollef $\mathrm{MH}$. The prevention of ventilator-associated pneumonia. N Engl J Med 1999;340:627-34.

8. Craven DE, Steger KA. Epidemiology of nosocomial pneumonia. New perspectives on an old disease. Chest 1995;108:1S-16S.

9. Kollef MH. Prevention of hospital-associated pneumonia and ventilator-associated pneumonia. Crit Care Med 2004;32:1396-405.

10. American Thoracic Society; Infectious Diseases Society of America. Guidelines for the management of adults with hospital-acquired, ventilator-associated, and healthcareassociated pneumonia. Am J Respir Crit Care Med 2005;171:388-416.

11. Young PJ, Rollinson M, Downward G, et al. Leakage of fluid past the tracheal tube cuff in a benchtop model. Br J Anaesth 1997;78:557-62.

12. Spray SB, Zuidema GD, Cameron JL. Aspiration pneumonia; incidence of aspiration with endotracheal tubes. Am J Surg 1976;131:701-3.

13. Elpern EH, Jacobs ER, Bone RC. Incidence of aspiration in tracheally intubated adults. Heart Lung 1987;16:527-31.

14. Mahul P, Auboyer C, Jospe R, et al. Prevention of nosocomial pneumonia in intubated patients: respective role of mechanical subglottic secretions drainage and stress ulcer prophylaxis. Intensive Care Med 1992;18:20-5.

15. Akdogan O, Ersoy Y, Kuzucu C, et al. Assessment of the effectiveness of a ventilator associated pneumonia prevention bundle that contains endotracheal tube with subglottic drainage and cuff pressure monitorization. Braz J Infect Dis 2017;21:276-81.
16. Bo H, He L, Qu J. Influence of the subglottic secretion drainage on the morbidity of ventilator associated pneumonia in mechanically ventilated patients. Zhonghua Jie He He Hu Xi Za Zhi 2000;23:472-4.

17. Bouza E, Perez MJ, Munoz P, et al. Continuous aspiration of subglottic secretions in the prevention of ventilatorassociated pneumonia in the postoperative period of major heart surgery. Chest 2008;134:938-46.

18. Deem S, Yanez D, Sissons-Ross L, et al. Randomized Pilot Trial of Two Modified Endotracheal Tubes To Prevent Ventilator-associated Pneumonia. Ann Am Thorac Soc 2016;13:72-80.

19. Fujimoto H, Yamaguchi O, Hayami H, et al. Efficacy of continuous versus intermittent subglottic secretion drainage in preventing ventilator-associated pneumonia in patients requiring mechanical ventilation: A single-center randomized controlled trial. Oncotarget 2018;9:15876-82 .

20. Girou E, Buu-Hoi A, Stephan F, et al. Airway colonisation in long-term mechanically ventilated patients. Effect of semi-recumbent position and continuous subglottic suctioning. Intensive Care Med 2004;30:225-33.

21. Gopal S, Luckraz H, Giri R, et al. Significant reduction in ventilator-associated pneumonia with the Venner-PneuX System in high-risk patients undergoing cardiac surgery: the Low Ventilator-Associated-Pneumonia study. Eur J Cardiothorac Surg 2015;47:e92-6.

22. Jena S, Kamath S, Masapu D, et al. Comparison of suction above cuff and standard endotracheal tubes in neurological patients for the incidence of ventilatorassociated pneumonia and in-hospital outcome: A randomized controlled pilot study. Indian J Crit Care Med 2016;20:261-6.

23. Koker A, Gok F, Erayman I, et al. Effect of subglottic secretion drainage for preventing ventilator-associated pneumonia. Crit Care 2014;18:19-20.

24. Kollef MH, Skubas NJ, Sundt TM. A randomized clinical trial of continuous aspiration of subglottic secretions in cardiac surgery patients. Chest 1999;116:1339-46.

25. Liu QH, He LX, Hu BJ, et al. Comprehensive prevention and pathogenesis of ventilator-associated pneumonia in elderly patients: a prospective, randomized, case-control clinical trial. Zhonghua Nei Ke Za Zhi 2006;45:717-20.

26. Liu SH, Yan XX, Cao SQ, et al. The effect of subglottic secretion drainage on prevention of ventilator-associated lower airway infection. Zhonghua Jie He He Hu Xi Za Zhi 2006;29:19-22.

27. Lorente L, Lecuona M, Jimenez A, et al. Influence of an endotracheal tube with polyurethane cuff and subglottic 
secretion drainage on pneumonia. Am J Respir Crit Care Med 2007;176:1079-83.

28. Mahmoodpoor A, Hamishehkar H, Hamidi M, et al. A prospective randomized trial of tapered-cuff endotracheal tubes with intermittent subglottic suctioning in preventing ventilator-associated pneumonia in critically ill patients. J Crit Care 2017;38:152-6.

29. Seyfi S, Latifi S, Shirkhani Z. Effect of subglottic secretion drainage on the ventilator-associated pneumonia in ICU patients. J Babol Univ Med Sci 2013;15:58-62.

30. Smulders K, van der Hoeven H, Weers-Pothoff I, et al. A randomized clinical trial of intermittent subglottic secretion drainage in patients receiving mechanical ventilation. Chest 2002;121:858-62.

31. Tao Z, Zhao S, Yang G, et al. Effect of two methods of subglottic secretion drainage on the incidence of ventilator-associated pneumonia. Zhonghua Jie $\mathrm{He} \mathrm{He} \mathrm{Hu}$ Xi Za Zhi 2014;37:283-6.

32. Valles J, Artigas A, Rello J, et al. Continuous aspiration of subglottic secretions in preventing ventilator-associated pneumonia. Ann Intern Med 1995;122:179-86.

33. Walaszek M, Gniadek A, Kolpa M, et al. The effect of subglottic secretion drainage on the incidence of ventilator associated pneumonia. Biomed Pap Med Fac Univ Palacky Olomouc Czech Repub 2017;161:374-80.

34. Yang CS, Qiu HB, Zhu YP, et al. Effect of continuous aspiration of subglottic secretions on the prevention of ventilator-associated pneumonia in mechanically ventilated patients: a prospective, randomized, controlled clinical trial. Zhonghua Nei Ke Za Zhi 2008;47:625-9.

35. Zheng RQ, Lin H, Shao J, et al. A clinical study of subglottic secretion drainage for prevention of ventilation associated pneumonia. Zhongguo Wei Zhong Bing Ji Jiu Yi Xue 2008;20:338-40.

36. Damas P, Frippiat F, Ancion A, et al. Prevention of ventilator-associated pneumonia and ventilator-associated conditions: a randomized controlled trial with subglottic secretion suctioning. Crit Care Med 2015;43:22-30.

37. Lacherade JC, De Jonghe B, Guezennec P, et al. Intermittent subglottic secretion drainage and ventilatorassociated pneumonia: a multicenter trial. Am J Respir Crit Care Med 2010;182:910-7.

38. Safdari R, Yazdannik A, Abbasi S. Effect of intermittent subglottic secretion drainage on ventilator-associated pneumonia: A clinical trial. Iran J Nurs Midwifery Res 2014;19:376-80.

39. Caroff DA, Li L, Muscedere J, et al. Subglottic Secretion Drainage and Objective Outcomes: A Systematic Review and Meta-Analysis. Crit Care Med 2016;44:830-40.

40. Dezfulian C, Shojania K, Collard HR, et al. Subglottic secretion drainage for preventing ventilator-associated pneumonia: a meta-analysis. Am J Med 2005;118:11-8.

41. Frost SA, Azeem A, Alexandrou E, et al. Subglottic secretion drainage for preventing ventilator associated pneumonia: a meta-analysis. Aust Crit Care 2013;26:180-8.

42. Leasure AR, Stirlen J, Lu SH. Prevention of ventilatorassociated pneumonia through aspiration of subglottic secretions: a systematic review and meta-analysis. Dimens Crit Care Nurs 2012;31:102-17.

43. Mao Z, Gao L, Wang G, et al. Subglottic secretion suction for preventing ventilator-associated pneumonia: an updated meta-analysis and trial sequential analysis. Crit Care 2016;20:353.

44. Muscedere J, Rewa O, McKechnie K, et al. Subglottic secretion drainage for the prevention of ventilatorassociated pneumonia: a systematic review and metaanalysis. Crit Care Med 2011;39:1985-91.

45. Wang F, Bo L, Tang L, et al. Subglottic secretion drainage for preventing ventilator-associated pneumonia: an updated meta-analysis of randomized controlled trials. J Trauma Acute Care Surg 2012;72:1276-85.

46. Alvarez Lerma F, Sanchez Garcia M, Lorente L. Guidelines for the prevention of ventilator-associated pneumonia and their implementation. The Spanish "ZeroVAP" bundle. Med Intensiva 2014;38:226-36.

47. Klompas M, Branson R, Eichenwald EC, et al. Strategies to prevent ventilator-associated pneumonia in acute care hospitals: 2014 update. Infect Control Hosp Epidemiol 2014;35 Suppl 2:S133-54.

48. Muscedere J, Dodek P, Keenan S, et al. Comprehensive evidence-based clinical practice guidelines for ventilatorassociated pneumonia: prevention. J Crit Care 2008;23:126-37.

49. Rello J, Lode H, Cornaglia G, et al. A European care bundle for prevention of ventilator-associated pneumonia. Intensive Care Med 2010;36:773-80.

50. Silvestri L, Piacente N, van Saene HK, et al. Intermittent subglottic secretion drainage and ventilator-associated pneumonia. Am J Respir Crit Care Med 2011;183:1435; author reply 6-7.

51. Taylor NJ, Auzinger G. Intermittent subglottic secretion drainage and ventilator-associated pneumonia. Am J Respir Crit Care Med 2011;183:1435-6; author reply 6-7.

52. Cook D, Ricard JD, Reeve B, et al. Ventilator circuit and secretion management strategies: a Franco-Canadian 
survey. Crit Care Med 2000;28:3547-54.

53. Krein SL, Kowalski CP, Damschroder L, et al. Preventing ventilator-associated pneumonia in the United States: a multicenter mixed-methods study. Infect Control Hosp Epidemiol 2008;29:933-40.

54. Baldwin F, Gray R, Chequers M, et al. Audit of UK ventilator care bundles and discussion of subglottic secretion drainage. Nurs Crit Care 2016;21:265-70.

55. Loupec T, Petitpas F, Kalfon P, et al. Subglottic secretion drainage in prevention of ventilator-associated pneumonia: mind the gap between studies and reality. Crit Care 2013;17:R286.

56. van Saene HK, Ashworth M, Petros AJ, et al. Do not suction above the cuff. Crit Care Med 2004;32:2160-2.

57. Berra L, Sampson J, Fumagalli J, et al. Alternative approaches to ventilator-associated pneumonia prevention. Minerva Anestesiol 2011;77:323-33.

58. Spapen H, Suys E, Nieboer K, et al. Automated intermittent aspiration of subglottic secretions and tracheal mucosa damage. Minerva Anestesiol 2013;79:316-7.

59. Seguin P, Perrichet H, Pabic EL, et al. Effect of Continuous versus Intermittent Subglottic Suctioning on Tracheal Mucosa by the Mallinckrodt TaperGuard Evac Oral Tracheal Tube in Intensive Care Unit Ventilated Patients: A Prospective Randomized Study. Indian J Crit Care Med 2018;22:1-4.

60. Greene R, Thompson S, Jantsch HS, et al. Detection of pooled secretions above endotracheal-tube cuffs: value of plain radiographs in sheep cadavers and patients. AJR Am J Roentgenol 1994;163:1333-7.

61. Ouanes I, Lyazidi A, Danin PE, et al. Mechanical influences on fluid leakage past the tracheal tube cuff in a benchtop model. Intensive Care Med 2011;37:695-700.

62. Zanella A, Scaravilli V, Isgro S, et al. Fluid leakage across tracheal tube cuff, effect of different cuff material, shape, and positive expiratory pressure: a bench-top study.

Cite this article as: Lacherade JC, Azais MA, Pouplet C, Colin G. Subglottic secretion drainage for ventilator-associated pneumonia prevention: an underused efficient measure. Ann Transl Med 2018;6(21):422. doi: 10.21037/atm.2018.10.40
Intensive Care Med 2011;37:343-7.

63. Duguet A, D'Amico L, Biondi G, et al. Control of tracheal cuff pressure: a pilot study using a pneumatic device. Intensive Care Med 2007;33:128-32.

64. Dragoumanis CK, Vretzakis GI, Papaioannou VE, et al. Investigating the failure to aspirate subglottic secretions with the Evac endotracheal tube. Anesth Analg 2007;105:1083-5, table of contents.

65. Muscedere JG, Day A, Heyland DK. Mortality, attributable mortality, and clinical events as end points for clinical trials of ventilator-associated pneumonia and hospital-acquired pneumonia. Clin Infect Dis 2010;51 Suppl 1:S120-5.

66. Branch-Elliman W, Wright SB, Howell MD. Determining the Ideal Strategy for Ventilator-associated Pneumonia Prevention. Cost-Benefit Analysis. Am J Respir Crit Care Med 2015;192:57-63.

67. Shorr AF, O'Malley PG. Continuous subglottic suctioning for the prevention of ventilator-associated pneumonia : potential economic implications. Chest 2001;119:228-35.

68. Hallais C, Merle V, Guitard PG, et al. Is continuous subglottic suctioning cost-effective for the prevention of ventilator-associated pneumonia? Infect Control Hosp Epidemiol 2011;32:131-5.

69. Kelley SD. Number needed to treat for subglottic secretion drainage technology as a ventilator-associated pneumonia prevention strategy. Crit Care 2012;16:446.

70. Speroni KG, Lucas J, Dugan L, et al. Comparative effectiveness of standard endotracheal tubes vs. endotracheal tubes with continuous subglottic suctioning on ventilator-associated pneumonia rates. Nurs Econ 2011;29:15-20, 37.

71. Mareiniss DP, Xu T, Pham JC, et al. Predicting Which Patients will Likely Benefit from Subglottic Secretion Drainage Endotracheal Tubes: A Retrospective Study. J Emerg Med 2016;50:385-93. 